Research Article

\title{
Safety Standard for Special Class Damslopes Based on Reliability Analysis
}

\author{
Lingzhi Huang, ${ }^{1}$ Zheng Si, ${ }^{1}$ Xiaoqi Du, ${ }^{1}$ Lifeng Wen $\mathbb{D}^{1},{ }^{1}$ and $\mathrm{Bin} \mathrm{Li}^{2,3}$ \\ ${ }^{1}$ State Key Laboratory of Eco-Hydraulics in Northwest Arid Region, Xi'an University of Technology, Xi'an 710048, China \\ ${ }^{2}$ Tianjin Port Engineering Institute Ltd. of CCCC First Harbor Engineering Company Ltd., Tianjin 30222, China \\ ${ }^{3}$ CCCC First Harbor Engineering Company Ltd., Tianjin 300461, China
}

Correspondence should be addressed to Lifeng Wen; wenxuan89@126.com

Received 20 November 2019; Revised 22 June 2020; Accepted 29 June 2020; Published 21 July 2020

Academic Editor: Heap-Yih (John) Chong

Copyright (c) 2020 Lingzhi Huang et al. This is an open access article distributed under the Creative Commons Attribution License, which permits unrestricted use, distribution, and reproduction in any medium, provided the original work is properly cited.

The risk of slope failure is determined by the degree of damage caused by the slope slide. For the special-high slope of some highrisk water conservancy and hydropower projects, the standard should be appropriately raised. Thus, the safety standard for these slopes is explored on the basis of reliability analysis. The slopes with high risk of failure are divided into special class I and special class II slopes depending on the risk levels and acceptable risk standards. The concept of reliability theory-based relative ratio of the safety margin is utilized to establish the relationship between annual failure probability and safety factor, thereby obtaining the reasonable safety factors for different slopes. Results show that the values of safety factors for special class I and special class II are 1.40 and 1.35, respectively. These results can provide a reference for exploring the safety standards of dams with a height of more than $200 \mathrm{~m}$.

\section{Introduction}

Geological disasters in the reservoir area are mainly manifested as natural disasters such as landslides and debris flows, which can directly lead to the instability of the bank slope of the reservoir, causing damage to water conservancy projects and eventually cause huge economic losses $[1,2]$. The class of the slope of the water conservancy and hydropower project shall be divided according to the location of the slope, importance of the slope, and degree of damage. In recent years, many earth and rockfill dams with a height of more than $200 \mathrm{~m}$ have been constructed in the world for hydropower generation, such as the Rogun Dam $(335 \mathrm{~m}$, Tajikistan), Rumei Dam (315 m, China), Nurek Dam (300 m, Tajikistan), Lianghekou Dam (295 m, China), Boruca Dam (267 m, Republic of Costa Rica), Chicoasen Dam (261 m, Mexico), and Tehri Dam (260 m, India) [3]. The construction of these reservoirs will form a series of hub engineering slopes, reservoir slopes, and river slopes. The stability of these slopes plays a pivotal role in engineering safety; therefore, it is necessary to appropriately improve the safety standards for these important slopes $[4,5]$.
The traditional safety factor method is commonly referred to as the safety factor $F$, which is expressed by the ratio of resistance to the action effect. For instance, the Chinese design specification for slopes of hydropower and water conservancy project uses a single safety factor to evaluate the slope stability and suggests that the minimum safety factor $F$ is 1.3 [6]. The Canadian Foundation Manual specifies an allowable safety factor of 1.35 to 1.50 for earth works including slopes [7]. The Hong Kong Slope Engineering Manual specifies a safety factor of 1.35 [8]. In this definition method, both resistance and force are expressed by a fixed value, and uncertainties such as calculation model and calculation parameters cannot be considered [9]. The allowable value of the safety factor is also determined by engineering experience, so the traditional safety factor method cannot fully reflect the design difference and sensitivity.

Lately, the reliability method and probability-based limit state design method that consider uncertainties have garnered attention $[10,11]$. The main approach typically involves the calculation of the reliability index using a numerical method, such as the Monte Carlo method [12], Taylor series method 
(FORM) [13], or point estimate method (PEM) [14, 15]. Based on the response surface methodology and first-order reliability method, Babu and Srivastava [16] performed reliability analyses for four selected rehabilitated earth dams. DelgadoHernández et al. [17] and Peyras et al. [18] explored risk assessment of earth dams based on a continuous Bayesian network; Chen et al. [19]optimized the point estimation method, solved the problem that a large amount of storage space is needed in the calculation process, and applied the point estimation method to embankment slope stability reliability analysis. Recently, several studies have introduced reliability theory into the assessment of ultrahigh dam slope stability. Chen [5] evaluated the values of reliability index of skewback antisliding stability and partial factor and proposed a computing method of structural reliability based on the traditional safety factor. Yi et al. [20] and Dekay and McClelland [21] developed a program combining slope stability and reliability analyses to evaluate safety factors of the critical slip surface. Li et al. [22] and Zhou et al. [23] investigated dams' risk acceptance criteria and risk classification. The authors of this paper have used the theory of relative ratio of safety margin to study the safety standard for slopes of ultrahigh earth and rockfill dams in China [24]. Huang and Xiong [25] studied the seismic sequence performance of earth dams under earthquake loading and proposed a new methodology for evaluating the seismic response of earth dams based on the performance-based approach and a stoichiometric vibration method. This new method of dynamic performance analysis of earth dams demonstrates that performance-based criteria and reliability evaluation can provide more objective indices for decision-making rather than using deterministic seismic acceleration time series as it is the current normal practice. To investigate the seismic liquefaction performance of earth dams under earthquake loading, we present a new methodology for evaluating the seismic response of earth dams based on a performance-based approach and a stochastic vibration method. This new method of dynamic performance analysis of earth dams demonstrates that performance-based criteria and reliability evaluation can provide more objective indices for decision-making rather than using deterministic seismic acceleration time series as it is the current normal practice. $\mathrm{Xu}$ et al. [26] demonstrated dynamic time-history analysis of random vibration based on failure probability theory. The failure probabilities of high concrete-faced rockfill dams with different failure grades based on three universal evaluation indices are determined by constructing a virtual generalized probability density evolution method process. At present, most of the research is to analyze the slope stability of the dam, but it does not involve these special class slopes that affect the safe operation of the reservoir and dam. It is necessary to study the stability safety standards of the special class slopes corresponding to these ultrahigh dams.

This paper proposes the acceptable safety standard of traditional deterministic analysis for the special class slopes based on risk analysis. We investigated the correlation between annual failure probability and safety factor based on the concept of reliability theory-based relative ratio of the safety margin and collected a portion of the specification's control criteria for slope failure risk. On this basis, we suggested that the failure probabilities of special class I and special class II slopes are $10^{-5}$ and $5 \times 10^{-5}$, respectively. Based on these acceptable risk standards, this paper studies the safety standard of the high slope in water conservancy and hydropower project and verifies the rationality of the proposed standard. This paper attempts to carry out a study on the values of reliability index and safety factor which are significant in the analysis on the stability of high slope.

\section{Risk Control Standard of Slope}

The safety and stability of the high slope should be emphasized in the construction of high dams with large reservoirs. In the design code for engineered slopes in water resources and hydropower projects [27], the slope is graded per the grade of hydraulic structure, and no upper limits exist to the technical standard of first-class projects. Therefore, the safety standard of slopes that affect the safe operation of dams should be raised. Besides, in the design codes for slope and earth-rockfill dams, no safety standards of slope have been approved. Thus, this section discusses the risk standard of slope failure from statistics and engineering safety.

In risk analysis and risk management, acceptable risk typically refers to the probability that a single life might be destroyed in 1 year and is used to explain the risk standard of a disaster. Owing to the absence of unified slope risk map and slope risk standard in China, this study aims to summarize the risk control standard of China based on relevant studies that started early and are relatively mature. Based on the 2004-2013 national geological disaster report released by the Ministry of Land and Resources of China [28], casualties of landslide hazard each year are obtained through the total casualties of geological disaster and the proportion of landslide hazard in geological disaster. Table 1 lists the casualties of landslide hazard from 2004-2013.

As shown in Table 1, approximately 400-1000 casualties of landslide hazard were reported each year. According to the risk map, the slope risk ranged from $10^{-5}$ to $10^{-6}$. After assessing the risks of various industries, Fell [29] proposed that the tolerable risk for a passive risk-taker (1 year) should range from $10^{-6}$ to $10^{-5}$. Based on the theory and practice of slope risk, Fell [29] proposed a risk control standard of slope (see Table 2). In addition, a correlation was established between the risk standard of slope and the regional economic development level. Typically, the disaster-related mortality in a country or a region fluctuates around $10^{-6}$ (see Table 3).

Based on the summarization and analysis of the slope risks of the regions and countries mentioned above and considering the risk standards adopted in other countries and China's economic development level, this study proposes that the acceptable risk of China's natural and engineering slopes in water conservancy and hydropower project, that is, yearly failure probability, should be set at $10^{-5}-10^{-6}$. For class 1 slope (dam height, $>200 \mathrm{~m}$ ), which exerts a marked impact on the hydraulic structure after breaking, a failure probability of $10^{-6}$ is accepted, considering the progress of the dam design level, construction technology, and management capabilities. 
TABLE 1: Statistics of the casualties of landslide hazard in China each year [28].

\begin{tabular}{lcc}
\hline Year & Casualties & Landslide risk $\left(10^{-5}\right)$ \\
\hline 2004 & 735 & 0.2 \\
2005 & 486 & 0.6 \\
2006 & 970 & 1.0 \\
2007 & 635 & 0.3 \\
2008 & 757 & 0.2 \\
2009 & 394 & 0.6 \\
2010 & 647 & 0.6 \\
2011 & 302 & 0.8 \\
2012 & 380 & 0.8 \\
2013 & 476 & 0.6 \\
\hline
\end{tabular}

TABLE 2: The risk control standard of slope proposed by Fell [29].

\begin{tabular}{|c|c|}
\hline Project & Acceptable yearly failure probability \\
\hline Slop & $\begin{array}{l}10^{-4} \text {, for people who live closely to the project } \\
10^{-6} \text {, for people who live far away from the } \\
\text { project }\end{array}$ \\
\hline $\begin{array}{l}\text { Slope bein } \\
\text { built }\end{array}$ & $\begin{array}{l}10^{-5} \text {, for people who live closely to the project } \\
10^{-6} \text {, for people who live far away from the } \\
\text { project }\end{array}$ \\
\hline
\end{tabular}

Zhou et al. [31] combined the calculated yearly risk $P_{y}$ with the risk $P$ using the following formula:

$$
P_{y}=\frac{P}{T} \times \frac{N_{d}}{T},
$$

where $T$ is the service life of slope and $N_{d}$ is the design base year.

As determining the service life of slope is challenging while calculating using formula (1), a conservative approach is to make $T=N_{d}$; then, formula (1) can be approximately expressed as follows:

$$
P_{y}=\frac{P}{N_{d}} .
$$

Typically, in water conservancy and hydropower project, the design base year of class 1 structure is 100 years. The failure probability of China's class 1 slope evaluated through formula (2) is $10^{-4}$. The comparison table of failure probability and reliability index revealed that the reliability index of class 1 slope is 3.7. Table 4 shows the annual failure probability and allowable reliability index $\left(\beta_{a}\right)$ for each special class structure.

\section{Slope Stability Analyses Based on a Safety Margin Criterion}

3.1. Ratio of Safety Margin Method. For the association mapping analysis of the safety standard, safety factor, and a reliability index of the slope, Chen et al. [11] proposed a ratio of safety margin method through which the risk control levels could be compared. The ratio of safety margin $\eta_{F}$ implies the ratio of the safety factor $(F)$ of slope antisliding stability to the acceptable margin of safety factor $\left(F_{a}\right)$. The ratio of safety margin can be expressed as follows:

$$
\eta_{F}=\frac{F}{F_{a}} .
$$

The safety factor attained through the reliability analysis is $\beta$, and the corresponding acceptable margin of safety factor is $\beta_{a}$; however, it is inappropriate to express the relative safety factor as $\beta / \beta_{a}$ because only the correlation of $\beta$ with $1-\Phi(\beta)$ has physical significance. Figure 1 presents the ratio of safety margin method demonstrating the correlation between $\eta_{R}$ and $\eta_{F}$.

Based on the safety factor sample listed in Figure 1, the reliability indexes $\beta$ and $\beta_{a}$ can be evaluated. As $\beta>\beta_{a}$, the corresponding area of the shadow region a is smaller than $1-\Phi\left(\beta_{a}\right)$. Assuming that, upon subtracting a $\Delta F$ from all safety factors in the sample, there will be a new safety factor sample $F^{\prime}=F-\Delta F$, suggesting that the $y$-axis has moved a $\Delta F$ toward the right side (see $Y^{\prime}$ in Figure 1). In this new coordinate system, the area of the shadow region $a+b$ on the left side of $Y^{\prime}$ is equal to $1-\Phi\left(\beta_{a}\right)$, which is $10^{-6}$ for class 1 structure. Then, $\Delta F$ can be evaluated through derivation. Based on formula (4), the ratio of safety margin $\eta_{R}$ (based on the reliability method) can be expressed as follows:

$$
\eta_{R}=\left(\beta-\beta_{a}\right) \sigma_{F}+1,
$$

where $\sigma_{F}$ is standard deviation of safety factor.

In Figure 1, the ratio of DC to BA approximates to $\eta_{R}$, and the ratio of $\mathrm{HG}$ to $\mathrm{FE}$ approximates to $\eta_{F}$. Thus, the ratio of the safety margin $\eta_{R}$ defined through formula (4) could be compared with the ratio of the safety margin obtained through the traditional method in one coordinate system. Thus, a conclusion could be drawn that the values of $F$ and $\beta$ adopted above are at the same risk control level and could provide a theoretical basis for the establishment of relevant codes.

3.2. Slope Model Verification. We evaluated the safety factor and reliability index through two simple slope models (see Figure 2), which are often used to validate the slope stability. In addition, the safety factors and reliability indexes were evaluated by the simplified Bishop method and Rosenblueth method in the 2D software STAB. Table 5 presents the calculation parameters. In this study, $F$ and $\beta$ are calculated using a nonlinear strength index (angle of internal friction $(\varphi)$ ) under normal and seismic conditions. The value of $\varphi$ can be calculated using the nonlinear equation $\varphi=\varphi_{0}-\Delta \varphi \lg \left(\sigma_{3} / p_{a}\right)$ [32], where $\varphi$ is the secant effective stress angle of internal friction, $\varphi_{0}$ is the value of $\varphi$ for $\sigma_{3}$ equal to one atmosphere, $\Delta \varphi$ is the reduction in $\varphi$ for a 10 -fold increase in confining pressure, $\sigma_{3}$ is the confining pressure, and $p_{a}$ is atmospheric pressure.

When the safety factor of class 1 slope is 1.3 (as is stipulated in the code) and the reliability index of class 1 slope is 3.7 (as mentioned above), the ratio of the safety margin $\eta_{F}$ (based on the deterministic method) and the ratio of the safety margin $\eta_{R}$ (based on the reliability method) can be calculated. If $\eta_{F}$ approximates or equals to $\eta_{R}$, the safety factor of class 1 slope is suitable to be set at 1.3. Next, we evaluated the safety factor and reliability 
TABLE 3: Average casualties and annual probability of different countries in recent years [30].

\begin{tabular}{lccc}
\hline Country or region & Average casualties & Population (million people) & Probability of death \\
\hline Japan & 150 & 150 & $1 / 1 \times 10^{-6}$ \\
Korea & 56 & 70 & $1 / 1 \times 10^{-6}$ \\
USA & $25-50$ & 250 & $1-2 \times 10^{-6}$ \\
Australia & $<1$ & 17 & $1 / 17 \times 10^{-6}$ \\
Canada & 5 & 30 & $1 / 6 \times 10^{-6}$ \\
Hong Kong & 1 & 5.8 & $1 / 6 \times 10^{-6}$ \\
\hline
\end{tabular}

TABLE 4: Definition of special class structures.

\begin{tabular}{|c|c|c|c|}
\hline Classes & Definition & $\begin{array}{c}\text { Annual failure } \\
\text { probability }\end{array}$ & $\beta_{a}$ \\
\hline $\begin{array}{l}\text { Special class } \\
1\end{array}$ & $\begin{array}{l}\text { The flood caused by the dam failure will cause a class } 1 \text { dam downstream to collapse, even with } \\
\text { an effective early warning } \\
\text { Dams with a height exceeding } 250 \mathrm{~m} \text { and a capacity exceeding } 1 \times 10^{9} \mathrm{~m}^{3}\end{array}$ & $10^{-8}$ & 4.70 \\
\hline $\begin{array}{l}\text { Special class } \\
2\end{array}$ & $\begin{array}{l}\text { The flood caused by the dam failure will not cause a class } 1 \text { dam downstream to collapse with an } \\
\text { effective early warning but will cause it to collapse with an ineffective early warning } \\
\text { The flood caused by the dam failure will cause a class } 2 \text { dam downstream to collapse even with an } \\
\text { effective early warning } \\
\text { Dams with heights in the range of } 200-250 \mathrm{~m} \text { and a capacity exceeding } 1 \times 10^{9} \mathrm{~m}^{3}\end{array}$ & $5 \times 10^{-8}$ & 4.45 \\
\hline
\end{tabular}

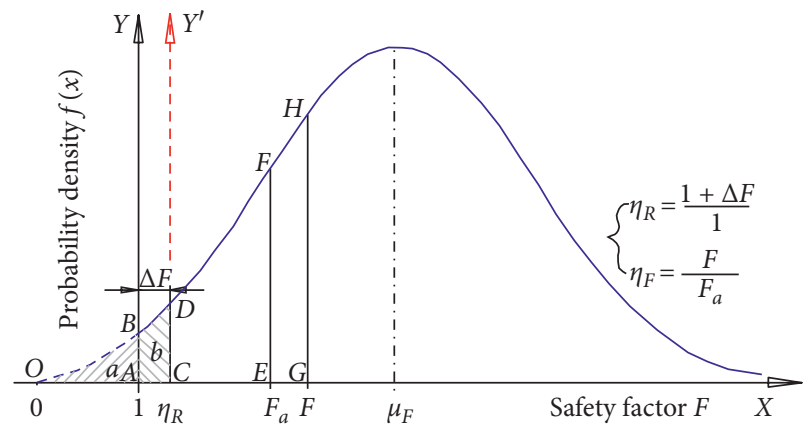

Figure 1: Diagram of $\eta_{R}-\eta_{F}$ based on the probability density function.

index of slope model through Figure 2. Table 6 lists the calculated ratio of safety margin $s \eta_{F}$ and $\eta_{R}$; the ratios of $\eta_{F}$ to $\eta_{R}$ of the two slope models approximate to 1 . Considering the impact of other factors, the results are acceptable, suggesting that the slope model has the same safety margin when the safety factor is 1.3 , and the reliability index is 3.7. Thus, safety factor 1.3 and reliability index 3.7 are at the same risk control level.

3.3. Engineering Verification. We conducted the example verification through the high slopes of dam abutment and spillway in the three hydropower stations-Nuozhadu, Shangzhai, and Lianghekou. The relative safety factors $\eta_{F}$ and $\eta_{R}$ of different fracture surfaces in different failure modes were evaluated under the safety factor 1.3 and the reliability index 3.7, respectively [33]. The numbers of calculated critical surfaces were 15,7 , and 5 , respectively $[5,24,34]$. The relative safety factors $\eta_{F}$ and $\eta_{R}$ of different fracture surfaces in different failure modes were evaluated under the safety factor 1.3 and the reliability index 3.7, respectively. In addition, we analyzed the stability of each dam slope based on the profile diagram (Figure 3) and statistical parameters (Table 7); the results of the two relative safety factors were linearly regressed. Furthermore, the safety factor 1.3 and the reliability index 3.7 were at the same risk control level if the fitted slope approximates to 1 .

Based on the ratio of safety margin theory and considering the impact of parameter variation, the relative safety factors, $\eta_{F}$ and $\eta_{R}$, were evaluated through the slope model of antisliding stability. The evaluated relative safety factors were linearly regressed (Figures 4-6).

The linear regression results revealed that the fitted slope of the calculated results of the three projects approximated to 1 , and the correlation coefficients were $>0.8$, suggesting that class 1 slope exhibits the same safety margin when the safety factor is 1.3 and the reliability index is 3.7. In addition, the risk control standards are at the same level when the reliability index of class 1 slope is set at 3.7, and the safety factor of class 1 slope is set at 1.3 (as stipulated in the code for slope).

\section{The Value of the Safety Factor of Special Class Dam Slope Stability}

We divided the special class slopes into special class I and special class II slopes based on the risk levels and acceptable risk standards. It is inappropriate for special class I and special class II slopes to adopt the same standard for failure probability and acceptable reliability index. The safety standard of the critical high slope in water conservancy and hydropower projects should be set per the relevant codes for high earth-rockfill dam. The authors of this paper have divided the dams with a height over $200 \mathrm{~m}$ into special classes 1 and 2 depending on the risk levels and acceptable risk standards; the annual failure probability for special 


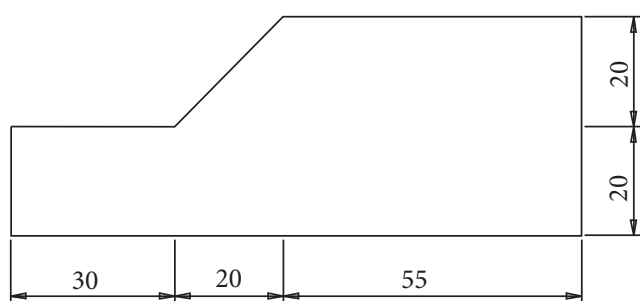

(a)

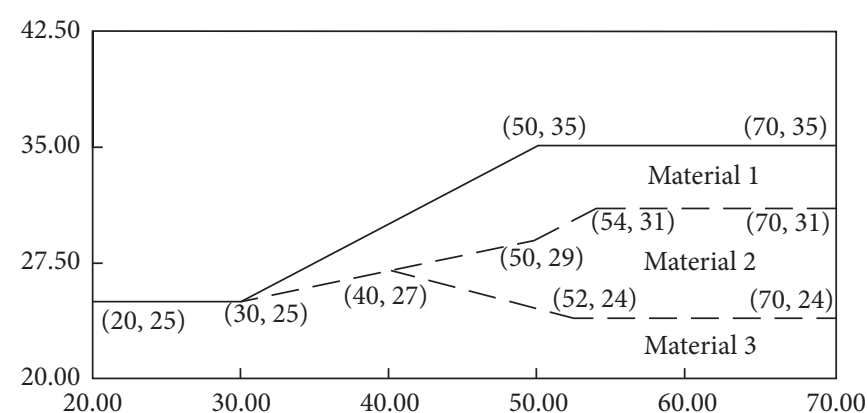

(b)

FIgURE 2: Two models for slope stability analyses: (a) simple slope, (b) layered soil slope.

TABLE 5: List of parameters used for the model calculation.

\begin{tabular}{lcccc}
\hline \multirow{2}{*}{ Parameters } & \multicolumn{2}{c}{$\varphi_{0}\left(^{\circ}\right)$} & \multicolumn{2}{c}{$\Delta \varphi\left(^{\circ}\right)$} \\
& Standard deviation & Mean of minimum values & Standard deviation & Mean of minimum values \\
\hline Simple slope & 2.0 & 51.0 & 1.0 & 11.0 \\
Material 1 & 2.0 & 51.0 & 1.0 & 11.0 \\
Material 2 & 1.8 & 53.0 & 1.0 & 13.0 \\
Material 3 & 1.6 & 54.0 & 1.0 & 15.0 \\
\hline
\end{tabular}

TABLE 6: Calculated results of the slope model.

\begin{tabular}{lccccc}
\hline \multirow{2}{*}{ Model } & \multicolumn{2}{c}{ Deterministic method } & \multicolumn{2}{c}{ Reliability method } & $\eta_{R}$ \\
& $F$ & $\eta_{F}$ & $\beta$ & 0.733 & $\eta_{F} / \eta_{R}=1.05$ \\
Model $a$ & 0.999 & 0.768 & 1.035 & 1.182 & $\eta_{F} / \eta_{R}=0.91$ \\
\hline
\end{tabular}

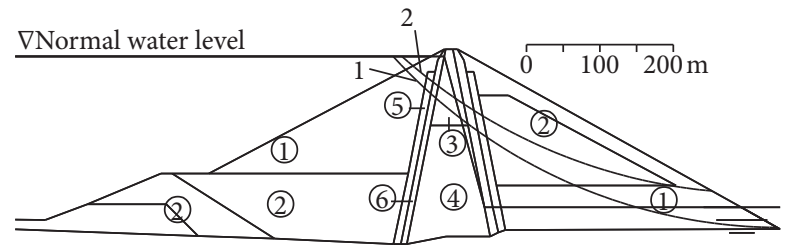

(a)

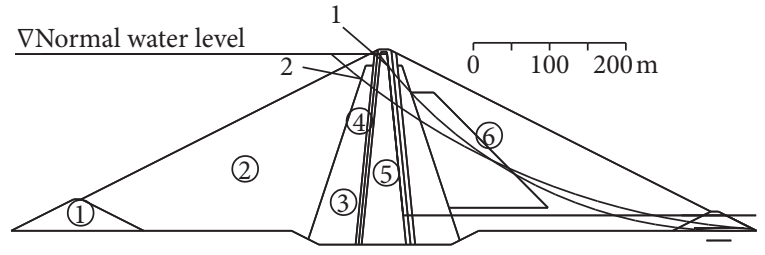

(b)

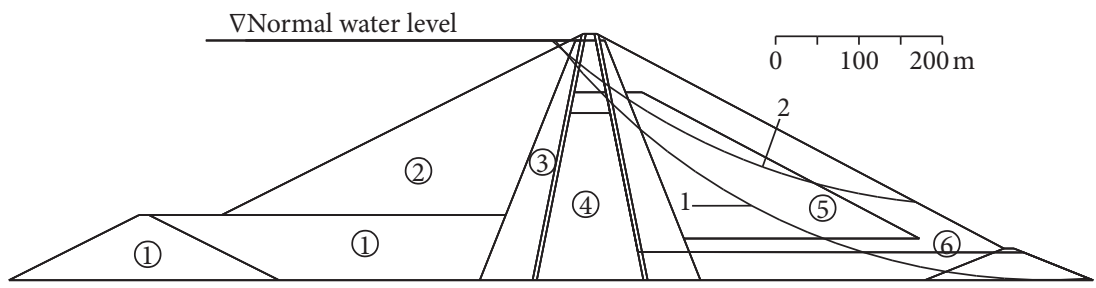

(c)

Figure 3: The profile diagram for the stabilities of the selected three ultrahigh dams in China with heights of more than 200 m: (1) critical slip surface under normal conditions; (2) critical slip surface under seismic conditions. (a) Nuozhadu. (b) Shangzhai. (c) Lianghekou.

classes 1 and 2 dams are $10^{-8}$ and $5 \times 10^{-8}$ respectively, and the corresponding reliability index is 4.7 and 4.45 [24]. As the grade of slope should be lower than that of the structure [35], the yearly failure probability of the acceptable risk level of special class I slope in special class 1 earth-rockfill dam is $10^{-7}$, and the corresponding reliability index is 4.2 . The yearly failure probability of the acceptable risk level of special class II slope in special class 2 earth-rockfill dam is $5 \times 10^{-7}$, and the corresponding reliability index is 3.95 . Hence, this section discusses the value of the safety factor through the ratio of safety margin method. Table 8 shows the risk control standards for stability of special dam and slope. 
TABLe 7: Statistical parameters of the three ultrahigh dams in China with heights of more than $200 \mathrm{~m}$.

\begin{tabular}{|c|c|c|c|c|c|}
\hline \multirow[t]{2}{*}{ Dam name } & \multirow[t]{2}{*}{ Dam height $(\mathrm{m})$} & \multirow[t]{2}{*}{ Material } & \multirow[t]{2}{*}{ Density $\rho\left(\mathrm{kg} / \mathrm{m}^{3}\right)$} & \multicolumn{2}{|c|}{$\begin{array}{c}\text { Nonlinear strength } \\
\text { parameters }\end{array}$} \\
\hline & & & & $\varphi_{0}\left({ }^{\circ}\right)$ & $\Delta \varphi\left(^{\circ}\right)$ \\
\hline \multirow{4}{*}{ Nuozhadu } & \multirow{4}{*}{261.5} & (1) and (2): upstream rockfill & 2150 & 52.0 & 8.5 \\
\hline & & (3): transition material & 2100 & 51.0 & 8.4 \\
\hline & & (4): filter material & 2080 & 50.0 & 8.3 \\
\hline & & (6): downstream rockfill & 2030 & 51.0 & 8.4 \\
\hline \multirow{4}{*}{ Shangzhai } & \multirow{4}{*}{254} & (1): coverage material & 2100 & 46.0 & 9.0 \\
\hline & & (2): main rockfill material & 2320 & 52.0 & 8.2 \\
\hline & & (3): secondary rockfill material & 2230 & 49.0 & 10.2 \\
\hline & & (4): downstream rockfill & 2120 & 46.0 & 9.0 \\
\hline \multirow{4}{*}{ Lianghekou } & \multirow{4}{*}{295} & (1): fine rockfill & 2000 & 51.5 & 8.4 \\
\hline & & (2): rockfill material II & 2110 & 49.1 & 9.1 \\
\hline & & (5): transition material & 2040 & 49.1 & 6.7 \\
\hline & & (6): filter material & 1940 & 49.9 & 10.1 \\
\hline
\end{tabular}

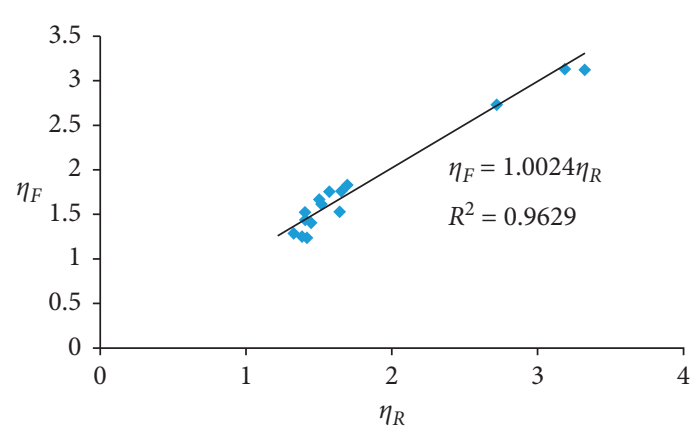

FIgURE 4: The correlation diagram of $\eta_{R}-\eta_{F}$ of the slope of the Nuozhadu hydropower station.

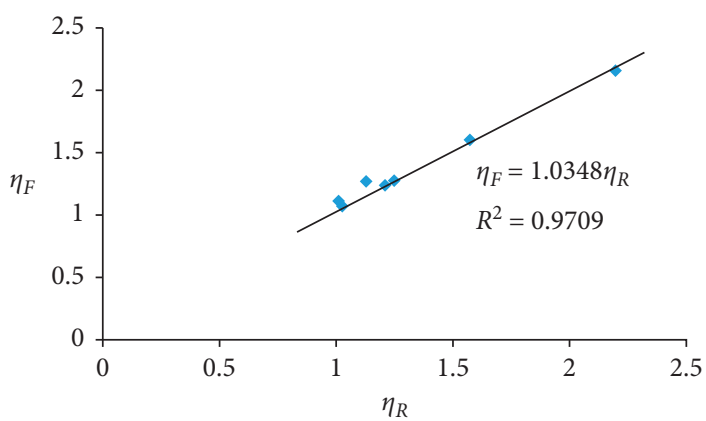

Figure 5: The correlation diagram of $\eta_{R}-\eta_{F}$ of the slope of the Shangzhai hydropower station.

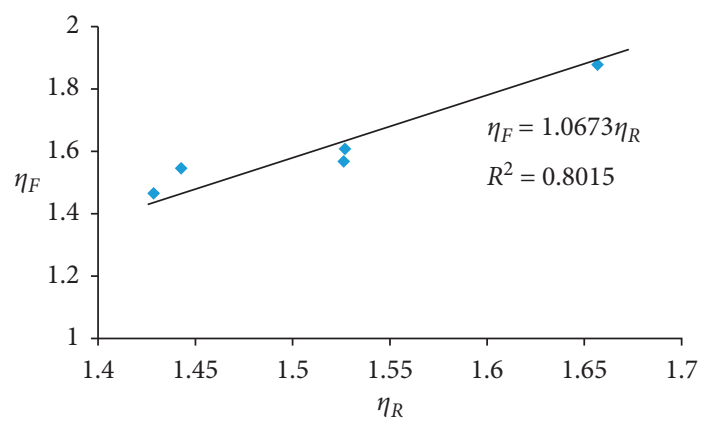

FIGURE 6: The correlation diagram of $\eta_{R}-\eta_{F}$ of the slope of the Lianghekou hydropower station. 
TABLE 8: Proposed value of risk control standards for stability of special dam and slope.

\begin{tabular}{lccc}
\hline Building type & Class & Yearly failure probability P & Reliability index \\
\hline \multirow{3}{*}{ Earth-rockfill dam } & Special class 1 & $10^{-8}$ & 4.70 \\
& Special class 2 & $5 \times 10^{-8}$ & 4.45 \\
& Class 1 & $10^{-7}$ & 4.20 \\
\hline \multirow{3}{*}{ Slope } & Special class I & $10^{-7}$ & 4.20 \\
& Special class II & $5 \times 10^{-7}$ & 3.95 \\
\hline
\end{tabular}

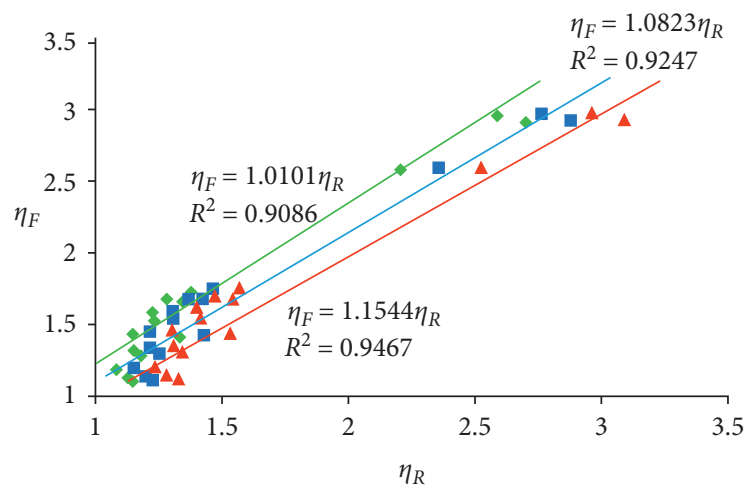

$$
\begin{aligned}
& \text { A } \beta_{a}=4.2, F_{a}=1.6 \\
& \text { - } \beta_{a}=4.2, F_{a}=1.5 \\
& \text { - } \beta_{a}=4.2, F_{a}=1.4
\end{aligned}
$$

Figure 7: The correlation of $\eta_{R}-\eta_{F}$ of the slope of the Nuozhadu hydropower station for different safety standards (special class I dam slopes).

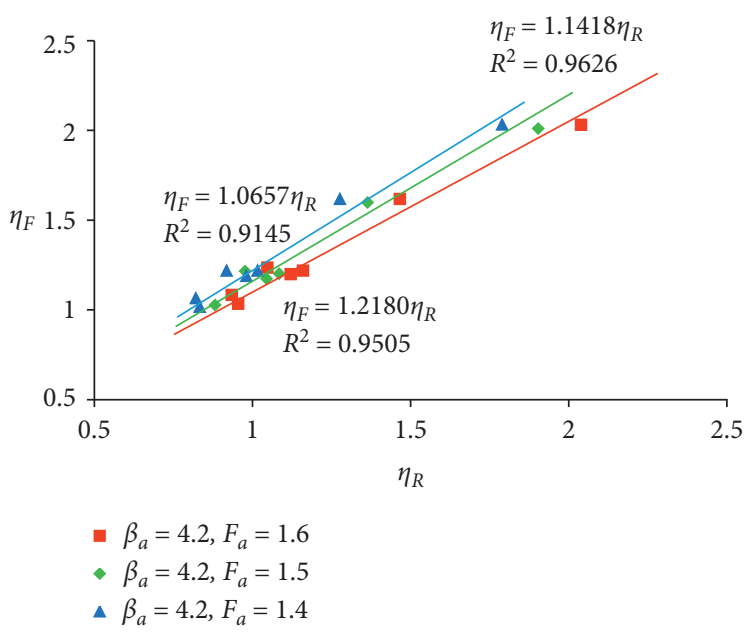

Figure 8: The correlation of $\eta_{R}-\eta_{F}$ of the slope of the Shangzhai hydropower station for different safety standards (special class I dam slopes).

4.1. Special Class I Dam Slope. Likewise, we selected the three projects mentioned in Section 3.3 as case studies to discuss the safety factor value of special class I dam slopes. We evaluated the safety factor ratios of the slopes of the three projects through the ratio of safety margin method. In addition, the ratio of safety margin (based on the reliability method) was calculated when the acceptable reliability index was 4.2. The ratio of safety margin (based on the deterministic method) was evaluated when the safety factors were
$1.4,1.5$, and 1.6, respectively. Furthermore, the results of the ratio of safety margin were linearly regressed (Figure 7-9). The results of the linear regression revealed that the fitted slopes of safety factor 1.4 and reliability 4.2 were the closest to 1 , and the correlation coefficients were the highest. Moreover, the slopes in the projects have the same safety margin when the safety factor is 1.4 , and the reliability index is 4.2 . Hence, it could be inferred that the safety factor 1.4 and the reliability index 4.2 are at the same risk control level. 


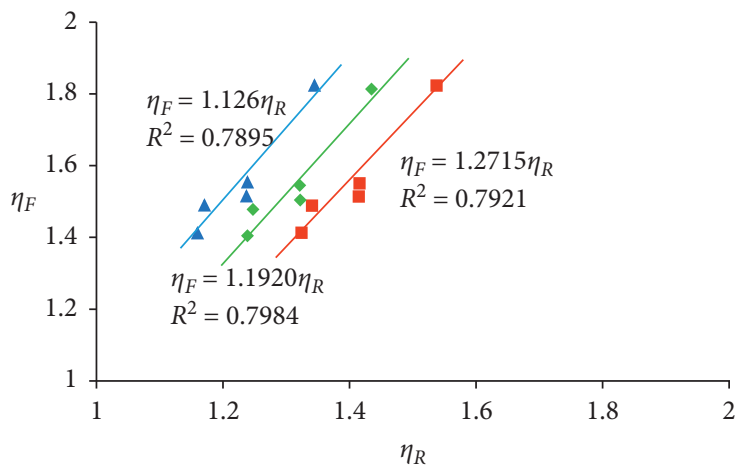

- $\beta_{a}=4.2, F_{a}=1.6$

- $\beta_{a}=4.2, F_{a}=1.5$

$\Delta \beta_{a}=4.2, F_{a}=1.4$

Figure 9: The correlation of $\eta_{R}-\eta_{F}$ of the slope of the Lianghekou hydropower station for different safety standards (special class I dam slopes).

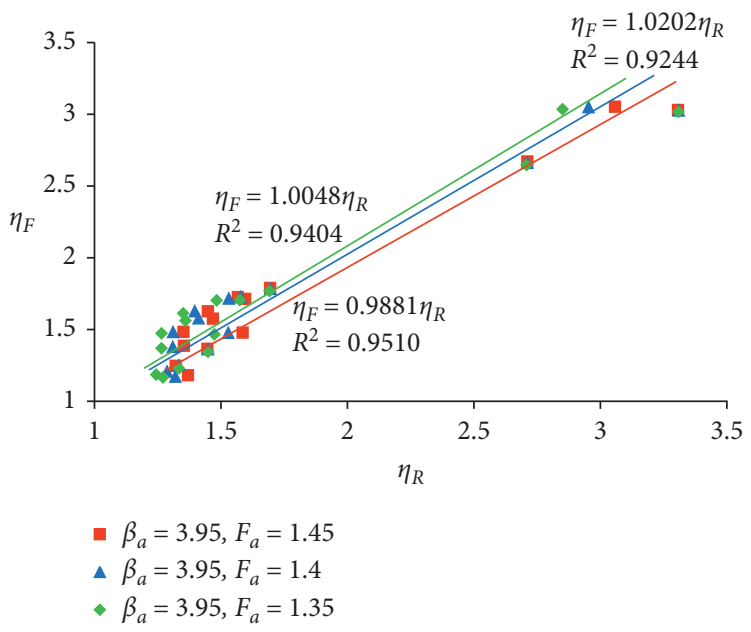

Figure 10: The correlation of $\eta_{R}-\eta_{F}$ of the slope of the Nuozhadu hydropower station for different safety standards (special class II dam slopes).

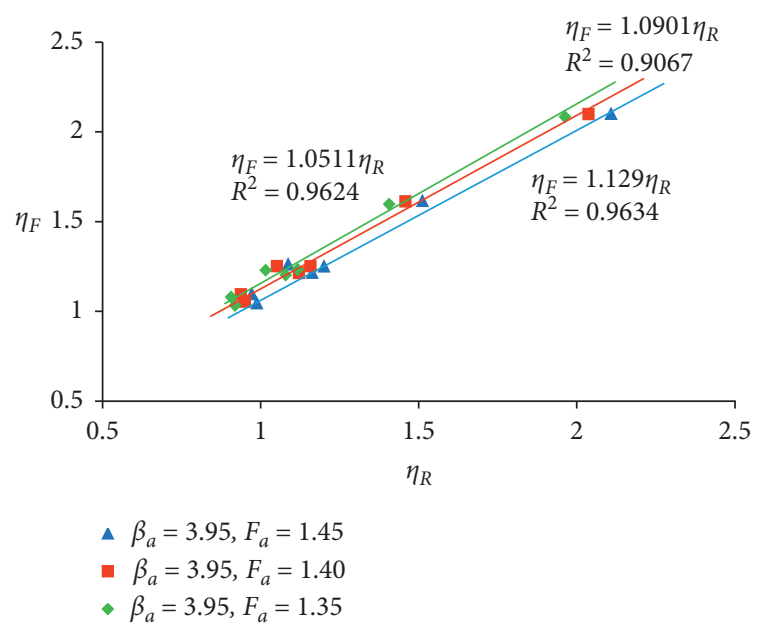

FIgURE 11: The correlation of $\eta_{R}-\eta_{F}$ of the slope of the Shangzhai hydropower station for different safety standards (special class II dam slopes). 


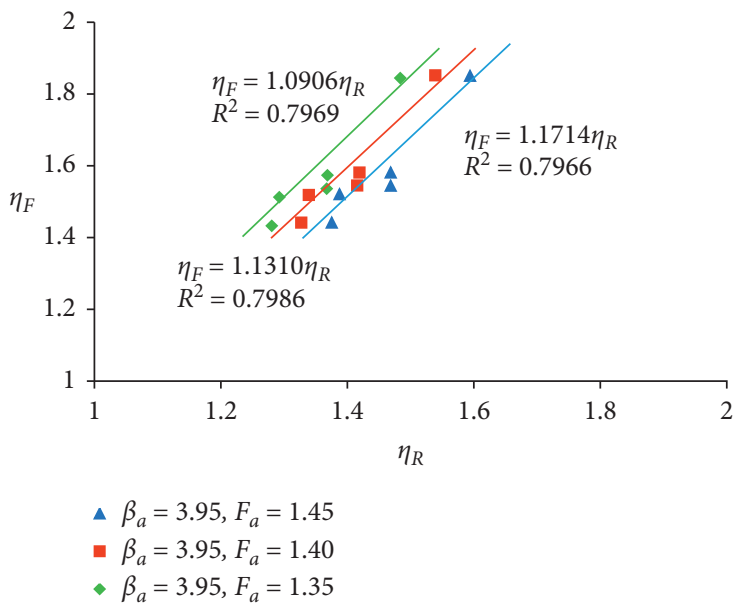

Figure 12: The correlation of $\eta_{R}-\eta_{F}$ of the slope of the Lianghekou hydropower station for different safety standards (special class II dam slopes).

4.2. Special Class II Dam Slope. We selected the three projects mentioned in Section 3.3 as case studies to discuss the safety factor value of special class II dam slopes. The safety factor ratios of the slopes of the three projects were evaluated using the ratio of safety margin method. In addition, we evaluated the ratio of safety margin (based on the reliability method) when the acceptable reliability index was 3.95 . The ratio of safety margin (based on the deterministic method) was evaluated when the safety factors were $1.35,1.4$, and 1.45 , respectively. Furthermore, the results of the ratio of safety margin were linearly regressed (Figure 10-12).

The results of the linear regression revealed that the fitted slopes of safety factor 1.35 and reliability 3.95 were closest to 1 , and the correlation coefficients were the highest. The slopes in the projects have the same safety margin when the safety factor is 1.35 , and the reliability index is 3.95. Hence, it can be inferred that the safety factor 1.35 and the reliability index 3.95 are at the same risk control level.

\section{Conclusions}

Based on risk levels and acceptable risk standards for ultrahigh dams, as well as the concept of the relative ratio of safety margin, this study evaluates the safety factor of the stability of special dam class slopes. From this study, the following inferences could be drawn.

For the natural and engineered slopes, the yearly failure probability of the acceptable slope risk level should be set at $10^{-6}$, and the corresponding reliability index and safety factor are 3.7 and 1.3, respectively. For the critical high slope in special class I, the yearly failure probability of the acceptable slope risk level is $10^{-7}$, and the acceptable reliability index is 4.2 . For the critical high slope in special class II, the yearly failure probability of the acceptable slope risk level is $5 \times 10^{-7}$, and the acceptable reliability index is 3.95 . The minimum safety factors of high slopes of special class I and special class II are suggested as 1.4 and 1.35 , respectively.

\section{Data Availability}

The data used to support the findings of this study are included within the article.

\section{Conflicts of Interest}

The authors declare no conflicts of interest.

\section{Acknowledgments}

This research was funded by the Key Project of National Natural Science Foundation of China (41731289), the National Natural Science Foundation of China, Excellent Young Scientists Fund (51722907), and the National Natural Science Foundation of China (51579207 and 51879217).

\section{References}

[1] R. Pang, B. Xu, X. Kong, Y. Zhou, and D. Zou, "Seismic performance evaluation of high CFRD slopes subjected to near-fault ground motions based on generalized probability density evolution method," Engineering Geology, vol. 246, pp. 391-401, 2018.

[2] R. Pang, B. Xu, X. Kong, and D. Zou, "Seismic fragility for high CFRDs based on deformation and damage index through incremental dynamic analysis," Soil Dynamics and Earthquake Engineering, vol. 104, pp. 432-436, 2018.

[3] Z. Y. Wu, Y. L. Li, J. K. Chen, H. Zhang, and L. Pei, "A reliability-based approach to evaluating the stability of high rockfill dams using a nonlinear shear strength criterion," Computers and Geotechnics, vol. 51, no. 2, pp. 42-49, 2013.

[4] Y. R. Liu, Z. He, Q. Yang, J. Deng, and L. Xue, "Long-term stability analysis for high arch dam based on time-dependent deformation reinforcement theory," International Journal of Geomechanics, vol. 17, no. 4, Article ID 04016092, 2017.

[5] Z. Y. Chen, "Reliability analysis and safety criterion in geotechnical engineering based on the index of safety margin," Chinese Journal of Rock Mechanics \& Engineering, vol. 37, no. 3, pp. 521-544, 2018.

[6] Planning and Design Institute of Water Conservancy and Hydroelectric Power under Ministry of Water Resources, 
WaterPower Specification for Design of Water Conservancy and Hydropower Engineering Slope (SL386-2007), China Water Power Press, Beijing, China, 2007.

[7] Canadian Geotechnical Society Foundations Committee, Canadian Foundation Engineering Manual, BiTech Publisher Ltd, Richmond, Canada, 2006.

[8] The Hong Kong Geotechnical Engineering Office, Geoguide5: Guide to Slope Maintenances, Government Publications Center, Hong Kong, China, 2003.

[9] B. Scott, B. J. Kim, and R. Salgado, "Assessment of current load factors for use in geotechnical load and resistance factor design," Journal of Geotechnical and Geoenvironmental Engineering, vol. 129, no. 4, pp. 287-295, 2003.

[10] A. H. Ang and W. H. Tang, Probability Concepts in Engineering Planning and Design, John Wiley \& Sons, New York, NY, USA, 1984.

[11] Z. Chen, L. Chen, J. Xu, P. Sun, C. Wu, and Y. Wang, "Quantitative deterministic versus Probability analyses based on a safety margin criterion," Science China Technological Sciences, vol. 57, no. 10, pp. 1988-2000, 2014.

[12] N. T. Kottegoda and R. Rosso, Applied Statistics for Civil and Environmental Engineers, Blackwell, Malden, MA, USA, 2008.

[13] R. E. Melchers and A. T. Beck, Structural Reliability Analysis and Prediction, John Wiley \& Sons, New York, NY, USA, 2018.

[14] K. K. Phoon and V. R. Johannes, Reliability of Geotechnical Structures in ISO2394, CRC Press, Boca Raton, FL, USA, 2016.

[15] International Organization for Standardization, General Principles on Reliability of Structures, International Organization for Standardization, Geneva, Switzerland, 2015.

[16] G. L. S. Babu and A. Srivastava, "Reliability analysis of earth dams," Journal of Geotechnical \& Geoenvironmental Engineering, vol. 136, no. 7, pp. 995-998, 2010.

[17] D. J. Delgado-Hernández, O. Morales-Nápoles, D. De-LeónEscobedo, and J. C. Arteaga-Arcos, "“A continuous Bayesian network for earth dams' risk assessment: an application,” Structure and Infrastructure Engineering: Maintenance, Management, Life-Cycle Design and Performance, vol. 10, no. 2, pp. 225-238, 2014.

[18] L. Peyras, C. Carvajal, H. Felix et al., "Probability-based assessment of dam safety using combined risk analysis and reliability methods-application to hazards studies," European Journal of Environmental and Civil Engineering, vol. 16, no. 7, pp. 795-817, 2012.

[19] Z. Chen, J. F. Du, and J. J. Yan, "Point estimation method: validation, efficiency improvement, and application to embankment slope stability reliability analysis," Engineering Geology, vol. 263, no. 20, Article ID 105232, 2019.

[20] P. Yi, J. Liu, and C. Xu, "Reliability analysis of high rockfill dam stability," Mathematical Problems in Engineering, vol. 2015, no. 1, 8 pages, Article ID 512648, 2015.

[21] M. L. Dekay and G. C. McClelland, "Predicting loss of life in cases of dam failure and flash flood," Risk Analysis, vol. 13, no. 2, pp. 193-205, 1993.

[22] S. Li, X. Zhou, Y. Wang, J. Zhou, X. Du, and Z. Chen, "Study of risk acceptance criteria for dams," Science China Technological Sciences, vol. 58, no. 7, pp. 1263-1271, 2015.

[23] X. B. Zhou, J. P. Zhou, and X. H. Du, "Study on dam risk classification in China," Water Science and Technology: Water Supply, vol. 15, no. 3, pp. 486-489, 2015.

[24] Y. Li, K. Li, L. Wen, B. Li, and Y. Liu, "Safety standard for slopes of ultra-high earth and rock-fill dams in China based on reliability analysis," International Journal of Civil Engineering, vol. 17, no. 12, pp. 1829-1844, 2019.
[25] Y. Huang and M. Xiong, "Probability density evolution method for seismic liquefaction performance analysis of earth dam," Earthquake Engineering \& Structural Dynamics, vol. 46, no. 6, pp. 925-943, 2017.

[26] B. Xu, R. Pang, and Y. Zhou, "Verification of stochastic seismic analysis method and seismic performance evaluation based on multi-indices for high CFRDs," Engineering Geology, vol. 264, Article ID 105412, 2020.

[27] China Institute of Water Resources and Hydropower Research, WaterPower Unified Standard for Reliability Design of Water Conservancy and Hydropower Engineering Structure (GB50199-1994), China Planning Press, Beijing China, 1994.

[28] Ministry of Land and Resources, Report on the 2004 2013 National Geological Disaster, Ministry of Land and Resources of China, Beijing, China, 2014.

[29] R. Fell, "Landslide risk assessment and acceptable risk," Canadian Geotechnical Journal, vol. 31, no. 2, pp. 261-272, 1994.

[30] X. B. Zhou, "Reliability and dam break based risk analysis of cascade reservoirs," Doctoral's thesis, Xi'an University of Technology, Xi'an, China, 2015.

[31] J. P. Zhou, H. Wang, and Z. Y. Chen, "Evaluations on the safety design standards for dams with extra height or cascade impacts part I: fundamentals and criteria," Journal of $\mathrm{Hy}$ draulic Engineering, vol. 46, no. 5, pp. 505-514, 2015.

[32] J. M. Duncan, S. G. Wright, and T. L. Brandon, Soil Strength and Slope Stability, pp. 36-37, Wiley, Hoboken, NJ, USA, 2014.

[33] The Ministry of Housing and Urban Rural Development of the People's Republic of China, Unified Design Standard for Reliability of Hydraulic Engineering Structures GB50199-2013, China Planning Press, Beijing, China, 2013.

[34] Z. Y. Chen, S. X. Yao, X. Lu et al., "Study on safety criteria for the acceptable factor of safety for high earth and rockfill dams," Journal of Hydraulic Engineering, vol. 50, no. 1, pp. 12-24, 2019.

[35] P. H. Bottelberghs, "Risk analysis and safety policy developments in The Netherlands," Journal of Hazardous Materials, vol. 71, no. 1-3, pp. 59-84, 2000. 